\title{
Teaching Author Rights Through 3D Printing Submissions
}

\section{CREATE}

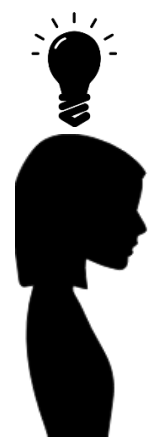

Student adapts existing model or designs a new model for 3D printing
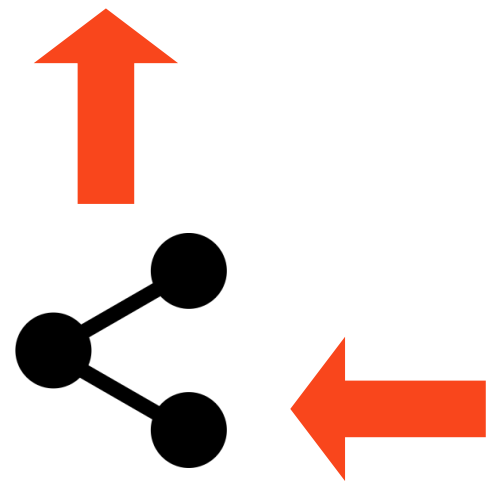

Share with the world; other students can adapt and print

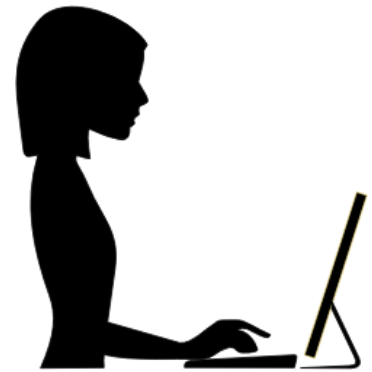

Student submits the file to the 3D printer queue in ScholarWorks, Boise

State's institutional repository

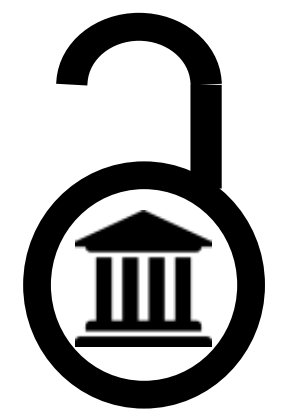

Post the work on the open access institutional repository

SHARE

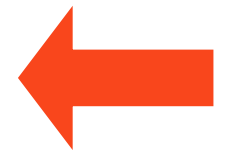

Help choose a Creative Commons License

EDUCATE

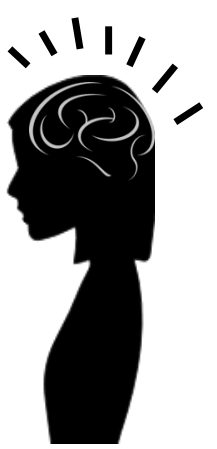

Librarians help print object and asks to include work in an open access institutional repository
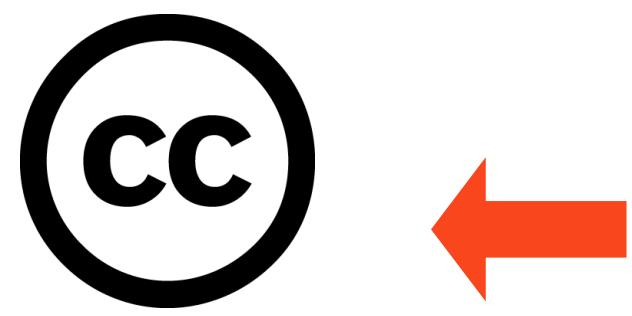

Empower student to take advantage of their copyrights

LICENSE 